\title{
KOMUNIKASI GEOGRAFI
}

\author{
Holy Rafika Dhona \\ Prodi Komunikasi Universitas Islam Indonesia \\ Jalan Kaliurang KM. 14,5 Sleman, Yogyakarta 55584 \\ Email: holy.rafika@uii.ac.id
}

\begin{abstract}
The development of communication and media technology changes spatial formations in human life. A local event becomes a global event in the media network. This condition gave rise to the field of study called by communication geography or media geography. This article is a theoretical review on this field from communication studies perspective. This paper described the growing assumption on the relationship between geography with communication studies. Moreover, this paper explained some basic assumptions of the field and proposed two alternatives the emerging sub-fields according to two scholars; Paul C. Adams and Andre Jansson. In the last, this paper recalled the importance of the field of communication geography in developing communication studies in Indonesia.
\end{abstract}

Keyword : communication, media, communication geography, space/place

\begin{abstract}
Abstrak
Perkembangan komunikasi dan teknologi media mengubah formasi spasial dalam kehidupan manusia. Acara lokal menjadi acara global dalam jejaring media. Kondisi ini memunculkan bidang studi yang disebut dengan komunikasi geografi atau media geografi. Artikel ini adalah tinjauan teoritis pada bidang ini dari perspektif studi komunikasi. Makalah ini menggambarkan asumsi yang berkembang pada hubungan antara geografi dengan studi komunikasi. Selain itu, ia menjelaskan beberapa asumsi dasar dari bidang studi ini dan mengusulkan dua alternatif sub-bidang menurut dua sarjana; Paul C. Adams dan Andre Jansson. Pada bagian akhir, tulisan ini mengingatkan kembali pentingnya bidang geografi komunikasi dalam perkembangan studi komunikasi di Indonesia.
\end{abstract}

Keyword : komunikasi, media, komunikasi geografi, ruang/tempat 


\section{PENDAHULUAN}

Komunikasi selalu terjadi dalam atau melalui ruang. Para pembelajar komunikasi mengenal betul bahwa komunikasi mempunyai konteks-konteks, apakah ia terjadi dalam sebuah organisasi, kelompok atau dalam sebuah kumpulan audience yang disebut sebagai 'massa' (Mulyana, 2009). Konteks-konteks tersebut sebenarnya adalah pembagian ruang atau pemberian batas dalam/melalui dan berdampak pada apa komunikasi yang dilakukan.

Ruang/tempat adalah dimensi penting komunikasi. Dengan menjadi 'konteks', sebuah lokasi/ruang/tempat tidak hanya menjadi lokasi terjadinya komunikasi, melainkan penentu proses komunikasi. Proses komunikasi ditentukan oleh batas apakah disebut sebagai 'kultur' atau 'wilayah geografi' tertentu. Ini telah diakui secara jamak. Misalnya, professor di Indonesia berarti adalah jabatan akademik, sebuah pencapaian administratif birokrasi layaknya jabatan dalam kerja. Sementara professor di wilayah lain, tak lain adalah gelar akademik yang dicapai dengan raihan-raihan akademik.

\begin{tabular}{ccc}
\multicolumn{2}{c}{ Ruang dalam hubungannya } \\
dengan komunikasi tidak hanya
\end{tabular} mempunyai dua fungsi (sebagai lokasi terjadinya komunikasi atau lokasi yang mempengaruhi komunikasi), tetapi ruang 'turut dibentuk' oleh proses komunikasi. Media atau tindak komunikasi membentuk ruang, baik ruang abstrak maupun ruang yang kemudian mengambil bentuk konkret. Sebagai contoh, surat kabal lokal membentuk 'batas pembaca lokal' sementara surat kabar nasional membentuk 'batas pembaca nasional'. Fenomena 'om telolet om' tidak hanya mempunyai ruang di jalan-jalan Pantai Utara Jawa, tetapi- karena media sosial- ia kemudian menjadi fenomena yang mempunyai keruangan global. Bangsa jajahan di Asia Tenggara, menurut Benedict Anderson (2002: 251), menemukan batas-batas nasionalismenya melalui tiga sistem komunikasi kuno, yakni cacah jiwa, peta, dan museum yang telah berubah bentuk ketika bangsa itu masuk zaman reproduksi mekanis alias percetakan modern. Komunikasi, dalam gagasan Anderson, adalah alat yang memudahkan pembayangan bersama sebagai sebuah bangsa (Anderson, 2002: 8)

Sampai di titik ini, kita sampai pada ambiguitas hubungan ruang dan komunikasi. Apakah ruang yang mempengaruhi komunikasi atau komunikasi yang memengaruhi dan bahkan membentuk ruang?

Pertanyaan inilah yang menjadi dasar munculnya wacana sub bidang studi komunikasi bernama komunikasi geografi (Falkheimer \& Jansson, 2006). Sebagai bidang studi yang baru diinstitusionalisasikan-meski sudah dipraktikkan sejak lama (Adams, 2009: 3-8), ulasan mengenai komunikasi geografi jarang didapatkan di Indonesia, atau bahkan bisa dikatakan tidak ada sehingga tidak ada payung yang menaungi para sarjana komunikasi yang resah terhadap masalah keruangan. Sementara itu, hampir setiap hari, kita dihadapkan pada persoalan ruang seperti konflik petani Kendeng, pembukaan Bandara di Kulonprogo Yogya, penjara yang berubah menjadi 'sangat nyaman' bagi koruptor dan pelaku narkoba, serta pengusiran atau relokasi orang-orang yang dilemahkan di banyak kota di Indonesia.

Umumnya, sarjana komunikasi yang mempersoalkan hal tersebut akan dibaca sebagai karya disiplin lain; studi urban atau studi tentang kota. Untuk itu, penegasan disiplin komunikasi dalam 
masalah keruangan penting demi perkembangan ilmu komunikasi di Indonesia sendiri.

Tulisan ini adalah perluasan penjelasan pendek penulis di tempat lain (Dhona, 2017). Sebagai perkenalan, tulisan ini didasarkan terutama pada beberapa karya kompilasi sarjana komunikasi geografi seperti Geographies Communication: The Spatial Turn in Media Studies (Falkheimer \& Jansson, 2006); Geographies of Media and Communication: A critical introduction (Adm, 2009) The Ashgate research companion to media geography (Adams, Craine, \& Dittmer, 2017); dan Communications/media/geographies

(Adams, Cupples, Glynn, Jansson, \& Moores, 2016), beberapa artikel jurnal produk sarjana komunikasi geografi, dan korespondensi pribadi penulis dengan dua sarjana yang turut membidani sub-disiplin ini, yakni Paul C Adams dan Andree Jansson.

Diskusi dalam tulisan ini terbagi dalam tiga bagian utama. Bagian pertama mendeskripsikan hubungan komunikasi dan geografi sebagai latar pemahaman sub-disiplin komunikasi geografi. Pada bagian kedua, tulisan ini menjelaskan asumsi dasar komunikasi geografi, terutama asumsi dasar dalam melihat ruang. Bagian terakhir, saya akan menyajikan dua alternatif pembagian bidang kaji komunikasi geografi sebagaimana yang ditawarkan oleh Paul C Adams dan Andre Jansson, dua sarjana dalam sub disiplin ini.

\section{Pembahasan}

\section{Hubungan Komunikasi dan Geografi}

Sebelumnya, saya hendak mengantisipasi masalah nama bagi subdisiplin ini. Ada sarjana yang menulis sub disiplin ini sebagai 'media geografi' dan ada pula yang menyebutnya sebagai 'komunikasi geografi' atau juga 'geografi komunikasi'. Buku yang ditulis bersama sarjana Komunikasi Geografi seperti Paul C Adams, Julie Cupples, Kevin Glynn, Andre Jansson, dan Shaun Moores pada 2017 juga menyandingkan istilah media dan komunikasi dalam "Communication, Media, Geographies”.

Paul C Adams, salah satu mantan Presiden Perhimpunan Geografer Amerika (American Association of Geographer AAG), awalnya, menggunakan istilah 'media' dalam taxonomy of communication geography (Adams, 2009). Ia mengemukakan pada penulis bahwa ketika memulai kelompok khusus bernama Communication Geography Specialty Group, yang menjadi unit AAG, ia lebih memilih istilah komunikasi ketimbang media. Media adalah istilah yang barangkali populer, sementara komunikasi terlihat tidak terlalu menarik dan jangggal, kuno, dan lebih tradisional. Meskipun demikian, komunikasi, menurut Adams, lebih baik karena ia adalah istilah yang lebih umum dimana media berada di samping hal penting lainnya, termasuk dalam istilah komunikasi adalah tanda, simbol, sinyal dimana non-human berkomunikasi, sementara kita biasanya berpikir bahwa hewan tidak menggunakan media. Komunikasi juga memasukkan ragam bahasa, dimana ketika kita menggunakan istilah media, para peneliti biasanya melupakan bahasa (Korespondensi pribadi, Desember 5 2016). 
Menimbang penjelasan Paul C Adams, dalam tulisan ini, saya akan lebih banyak menyebutnya sebagai komunikasi geografi ketimbang media geografi. Istilah ini juga tampaknya lebih relevan untuk mengaitkan dengan disiplin yang di Indonesia diberi nama sebagai 'ilmu komunikasi' dibandingkan sebagai 'studi media'.

Komunikasi geografi adalah lapangan studi komunikasi/media yang berkonsentrasi pada bagaimana komunikasi memproduksi ruang dan bagaimana ruang memproduksi komunikasi (how communication produces space and how space produces communication) (Falkheimer \& Jansson, 2006: 7; Jansson, 2005: 1)). Ia adalah cabang disiplin komunikasi sebagai hubungan antara beragam disiplin ilmu, terutama komunikasi dan geografi. Dengan definisi seperti ini, para sarjana komunikasi geografi mengakui bahwa ada hubungan yang erat antara komunikasi dengan geografi. Pertanyaannya kemudian: bagaimana hubungan tersebut terjadi?

Pertama, komunikasi dan geografi merupakan disiplin yang berbagi subjek dan metodologi yang sama (Adams \& Jansson, 2012). Para sarjana komunikasi geografi berkeyakinan bahwa komunikasi dan geografi tidak hanya dua disiplin yang hanya 'bertetangga', tetapi mempunyai objek atau perhatian yang sama, yakni relasi komunikasi/mediasi dan ruang. Menurut Adams dan Jansson, banyak karya sarjana komunikasi yang menggunakan istilah geografi melalui istilah "balikan spasial/ruang" (spatial turn), sementara dalam literatur geografi muncul istilah balikan komunikasi (communication turn) yang merupakan istilah komunikasi (Adams \& Jansson, 2012: 300). Ini berarti bahwa studi komunikasi dan media telah lama mempermasalahkan masalah ruang, misalnya, dalam istilah 'konteks budaya', 'lokalitas' atau 'globalisasi'. Sementara itu, studi geografi banyak mempermasalahkan bagaimana komunikasi dan media mempengaruhi individu dalam mempersepsi dan memperlakukan ruang, utamanya dari cabang geografi kemanusiaan (human geography). Namun, selama ini, kebersatuan (intradisiplineritas) kedua disiplin itu hanya tampak secara implisit dalam agenda riset. Hal ini tampaknya juga berlaku di Indonesia. Studi-studi mengenai Public Relations dengan menggunakan perspektif Indonesia yang dilakukan Kriyantono \& McKenna (2016) atau tulisan Kusuma \& Vitasari (2016) melihat media daring sebagai ruang yang berbeda dari media konvensional.

Kedua, sifat inheren disiplin komunikasi sendiri adalah multidisiplin, dan, dalam rangka multidisiplineritas itu, hubungan komunikasi dengan geografi bahkan lebih tua daripada istilah disiplin 'komunikasi' yang maknanya relatif stabil hanya pada pertengahan abad ke-20. Kita dapat melihat fakta ini pada temuan subdisiplin sejarah komunikasi (communication history), yang objek studinya tidak hanya terpaku pada 'media' dan 'komunikasi' sebagaimana studi komunikasi pasca-Perang Dunia Kedua.

Menurut para sejarawan komunikasi, pada abad ke-19, karena teknologi interaksi manusia adalah percetakan dan instrumen transportasi, apa yang dinamakan sebagai praktik komunikasi adalah studi mengenai jalan, rel selain percetakan yang menjamur kala itu. Komunikasi, pada abad ini, bermakna segala hal yang membuat manusia dapat berhubungan dan melakukan pertukaran, yang menjadi objek studi geografer (Simonson (ed.). 2013: 13-57). 
Ketika studi komunikasi mulai dominan mempelajari media baru (radio) pada 1930-an, disiplin geografi tetap tak beranjak dari fokusnya pada praktik komunikasi lama (jalan dan rel kereta api). Argumen lain tentang keterpisahan komunikasi dengan realitas geografis barangkali dengan tepat dijelaskan oleh James Carey (2009, h. 157), "Fakta paling penting mengenai telegraf adalah ketika telegraf...mempersilakan untuk pertama kalinya keterpisahan komunikasi dari transportasi secara efektif". Ini berarti bahwa komunikasi berpisah dengan realitas geografis tidak pada 1930-an, melainkan pertengahan abad ke-19.

Hingga sekarang, dalam disiplin geografi terdapat sub-disiplin geografi komunikasi, yang dianggap sebagai cabang dari geografi kemanusiaan. Hanya saja, studi disiplin geografi ini di Indonesia barangkali terbatas hanya pada analisis lokasional (tempat terjadinya komunikasi), pesan, kuantitas dan kualitas informasi. Ini bisa dilihat dari kutipan Diktat Pembelajaran Geografi Komunikasi berikut.

... bahwa tidak semua wilayah kajian Ilmu Komunikasi dipelajari dalam Geografi Komunikasi, mengingat bahwa yang dipentingkan dalam geografi komunikasi adalah ruang tempat terjadinya komunikasi (analsisis lokasional), aliran atau transmisi informasi atau pesan, kuantitas dan kualitas aliran informasi antar ruang, distribusi fasilitas media komunikasi dan efek media masa terhadap tingkah laku keruangan manusia dan lingkungan (Hadi, Bambang Saeful. 20o6, h. 3).

Tulisan ini merupakan pembahasan berdasarkan perkembangan terbaru dari disiplin komunikasi dan bergerak dari asumsi dasar para sarjana komunikasi geografi bahwa ruang merupakan produk yang berubah atau tidak tetap. Dengan demikian, komunikasi geografi harus dilihat sebagai tidak semata melihat ruang sebagai lokasi terjadinya komunikasi sebagaimana disebutkan Hadi di atas.

Ketiga, hubungan komunikasi dan geografi terutama dipertemukan oleh para sarjana teori sosial yang mengemukakan bahwa ruang tidaklah tetap/berubah dan unsur pengubahnya terutama adalah komunikasi. Gagasan ini, misalnya, tampak pada cara berpikir figur teoretisi ruang yang populer seperti Henri Lefebvre (1901-1991) dan Doreen Massey (1944 2016).

Lefebvre menggarisbawahi bahwa, dalam pembentukan ruang, ruang natural telah dirusak dan diubah menjadi sebuah produk sosial melalui seperangkat teknikteknik, khususnya teknik yang berhubungan dengan fisik dan sains informasi (information science) (Elden, 2004: 184). Ini berarti bahwa Lefebvre menaruh perhatian pada informasi, objek material dari disiplin komunikasi, menjadi kekuatan pembentuk ruang.

Sementara Doreen Massey, yang merupakan pembaca Louis Althusser, seorang tokoh marxis strukturalis Prancis, menggagas 'ruang relasional' (relational space), dimana ruang terbentuk atas adanya jejaring koneksi dan relasi yang berarti ruang dapat terwujud dengan adanya komunikasi.

\section{Asumsi Dasar Komunikasi Geografi: Ruang Sebagai Produk Sosial}

Sebagaimana disebutkan sebelumnya, komunikasi geografi adalah studi mengenai bagaimana komunikasi memproduksi ruang, dan bagaimana ruang memproduksi komunikasi? Dari definisi tersebut, dasar asumsi komunikasi geografi adalah ruang/tempat tidaklah 
alamiah atau ruang tidak selamanya stabil. Ruang adalah produk dari kehidupan sosial, dan bukan hanya tempat dimana kehidupan berlangsung.

Pandangan ini berbeda dengan gagasan geografi klasik yang menganggap ruang/tempat sebagai sesuatu yang tetap atau tidak berubah. Komunikasi geografi menolak gagasan dimana representasi ruang/tempat via media/mediasi bukanlah keruangan yang asali (placelessness) sebagaimana gagasan fenomenologgeografer Edward Relph (1976). Relph menyatakan bahwa keruangan haruslah dialami, dihayati personal. Oleh karenanya, keruangan yang ditampilkan dan disebarkan melalui mediasi (iklan rumah atau promosi destinasi wisata, misalnya) tidak dapat menggantikan ruang yang asali tersebut.

Para sarjana komunikasi geografi justru menerima kenyataan bahwa placelessness merupakan kenyataan material dari ruang yang harus diterima dengan lapang dada. Mediasi sebuah ruang mampu memproduksi keruangan tertentu, dan bahkan menuntun aksi manusia dalam memperlakukan ruang. Dengan bahasa yang lebih sederhana, para sarjana komunikasi geografi meyakini bahwa 'mediasi ruang' adalah ruang itu sendiri.

Paul C Adams dan Andre Jansson (2012) menganjurkan para sarjana komunikasi agar "merestrukturisasi paradigma riset dalam geografi dan media/komunikasi untuk membangun sebuah jembatan antara dua disiplin tersebut”. Keduanya dan para sarjana komunikasi geografi lainnya, tidak ingin menggantikan disiplin komunikasi atau studi media, melainkan mengikutsertakan perspektif geografis dalam melihat komunikasi/media atau 'perspektif spasial'. Perspektif ini bisa disebut sebagai sebuah perspektif baru dalam studi komunikasi/geografi.

Untuk mengetahui bagaimana perspektif itu dapat disebut baru, pembaca studi komunikasi geografi selayaknya memahami bagaimana pandangan para sarjana komunikasi geografi membangun dalam membangun tiga tahapan sejarah dalam penelitian komunikasi. Tahap pertama dalam studi komunikasi adalah tahap pendekatan transmisi, tahap kedua adalah tahap pendekatan ritual, dan tahap ketiga adalah pendekatan spasial (Falkheimer dan Jansson, 2006; Jansson, 2012). Dalam ketiga tahap ini, ruang diperlakukan oleh para sarjana komunikasi dengan cara yang berbeda. Tahap ketiga, tahap spasial, menjadikan komunikasi geografi sebuah perspektif yang unik yang harus dibedakan dengan 'studi komunikasi dengan perspektif kebudayaan' yang diletakkan dalam tahap kedua (tahap pendekatan ritual/kontekstual/kultural)..

Tahap pendekatan transmisi, yang diklaim sebagai pendekatan paling mula dalam studi komunikas, kadang tidak membahas ruang sama sekali. Dalam pendekatan transmisi, ruang hanya dilihat sebagai lokasi terjadinya komunikasi. Penelitian-penelitian dalam model pertama atau model transmisi diwakili oleh diktum Harold Laswell yang mengatakan "Who says what to whom, through which channel, and with what effect?". Model transmisi ini sangat dominan dalam riset media sejak 1920-an hingga sekarang. 


\section{Bagan 1. Tahapan Model Komunikasi dari Transmisi Ke Spasial}

\begin{tabular}{lll}
\hline Tahapan Model & Asumsi Terhadap Ruang & \multicolumn{1}{c}{$\begin{array}{c}\text { Hubungan Ruang dan } \\
\text { Komunikasi }\end{array}$} \\
\hline Model Transmisi & $\begin{array}{l}\text { Ruang adalah sesuatu yang } \\
\text { stabil }\end{array}$ & $\begin{array}{l}\text { Ruang hanya menjadi lokasi } \\
\text { terjadinya peristiwa komunikasi }\end{array}$ \\
$\begin{array}{l}\text { Model } \\
\text { Ritual/Kontekstual }\end{array}$ & $\begin{array}{l}\text { Ruang adalah Sesuatu yang } \\
\text { Stabil }\end{array}$ & $\begin{array}{l}\text { Ruang turut memberi makna pada } \\
\text { komunikasi }\end{array}$ \\
Model Spasial & $\begin{array}{l}\text { Ruang adalah sesuatu yang } \\
\text { diciptakan dan dapat berubah }\end{array}$ & $\begin{array}{l}\text { Ruang dan komunikasi terhubung } \\
\text { secara resiprokal dan ambigu. } \\
\text { Ruang mempengaruhi komunikasi, } \\
\text { komunikasi juga membentuk ruang }\end{array}$ \\
\hline
\end{tabular}

Model ini terfokus pada perluasan linear pesan dalam sebuah ruang. Dengan metode kuantitatif, eksperimental, dan fungsionalistik, model ini hanya akan mendapatkan kesimpulan yang terisolasi secara teoretis, dari teks dan konteks yang berkaitan dengan ruang. Model ini dirasa kurang cocok lagi untuk melihat kompleksitas keseharian dan komposisi transformasi kebudayaan dari masyarakat, dimana masyarakat sekarang berada dalam tahap multi-ruang (hyper-space)

Model kedua adalah model ritual atau kontekstual atau kultural. Dalam model ini, studi komunikasi sudah menyadari ruang sebagai faktor penting mediasi/komunikasi. Hanya saja, ruang tetap dilihat sebagai sesuatu yang tetap, atau tak berubah. Model ini bisa disebut juga sebagai pendekatan kontekstual, dimana proses komunikasi selalu didefinisikan 'tergantung konteksnya' atau 'tergantung budaya'-nya. Falkheimer dan Jansson mendasarkan model kontekstual ini pada formula dari James W Carey, $A$ Cultural Approach to Communication (1975) dan-tentu saja, pemikiran tokohtokoh Birmingham Center for Cultural Studies (Cultural Studies).
James Carey mengkritik model transmisi dengan mengatakan studi komunikasi harusnya tidak hanya melihat pada perluasan pesan dalam ruang, tetapi juga perkembangan sebuah masyarakat dalam konteks waktu. Dengan meletakkan perkembangan sebuah masyarakat, Carey menyadari bahwa kebudayaan dalam konteks lokal tertentu turut mempengaruhi proses komunikasi.

Serupa dengan James W Carey, kelompok Cultural Studies dengan konsep encoding-decoding Stuart Hall, misalnya, mendorong studi komunikasi untuk melihat "konteks" ketimbang "teks". Konteks budaya seseorang, dalam hal ini infrastruktur teknis, relasi produksi dan bingkai pengetahuan yang hegemonik dilihat Stuart Hall (2005) sebagai penentu makna pesan bagi seorang individu. Oleh karenanya, makna orang Indonesia akan berbeda dengan makna orang Amerika meski dihadapkan pada pesan/teks yang sama. Namun, gagasan James W Carey dan Cultural Studies mengasumsikan 'konteks' sebagai sesuatu yang tetap. 'Konteks' berarti adalah kebudayaan kelompok masyarakat tertentu, dan biasanya akan didefinisikan berdasarkan keruangan tertentu yang tetap dan tidak berubah. Artinya, ruang dalam pendekatan ritual/kontekstual/kultural masih dilihat 
sebagai sesuatu yang tetap dan stabil. Lebih jauh, pendekatan kultural tidak dapat melihat ambiguitas ruang dalam teknologi komunikasi yang berkembang sekarang. Kenyataan ini yang mendorong beberapa sarjana komunikasi mulai beralih pada model ketiga, yakni model spasial.

Pada komunikasi model spasial, ruang dilihat sebagai sesuatu yang tidak stabil. Ruang dikonstruk oleh faktor eksternal dan ruang yang menjadi tempat terjadinya komunikasi yang juga tidak stabil sehingga konteks yang merupakan 'ruang/batas tempat terjadinya komunikasi', apakah itu material (wilayah) atau simbolik (hierarki, kuantitas dsb), yang relatif stabil menjadi goyah. Pada tahap spasial, hubungan komunikasi dan ruang tempat terjadinya komunikasi adalah resiprokal dan ambigu.

Permulaan tahap model spasial ditandai oleh publikasi dua karya setelah 1985, yakni buku yang dieditori oleh Burgess and Gold, Geography, the Media and Popular Culture dan Joshua Meyrowitz, No Sense of Place. Dua buku ini dianggap sebagai penanda pendekatan baru dalam studi komunikasi, di luar transmisi dan kultural karena beberapa alasan.

Buku Geography, the Media and Popular Culture, menginisiasi pentingnya media yang bertentangan dengan pendekatan behavioristik dan intepretif yang menjadi gagasan dominan dalam geografi. Kedua pendekatan ini, menurut Burgess dan Gold, lebih melihat media atau komunikasi dalam fungsinya sebagai 'sarana' yang digunakan untuk memanipulasi kondisi ruang.

Pendekatan behavioristik dalam geografi, biasanya mengkategorikan informasi mengenai ruang/tempat dalam media dengan dua konsep, yakni 'citra' dan 'stereotip'. Citra dapat diperlakukan sebagai data/sumber informasi, sementara stereotip dimaknai sebagai generalisasi mengenai orang atau tempat sebagaimana dilakukan dalam psikologi sosial. Media “...utamanya berimplikasi pada produksi dan pemeliharaan stereotif karena menciptakan matriks budaya yang luas dimana gambar berubah berbeda dari kenyataan yang seharusnya mereka wakili" (Burgess \& Gold, 1985: 10). Singkatnya, pendekatan ini melihat mediasi ruang hanyalah gambaran palsu dari ruang yang riil.

Sementara itu, pendekatan interpretif/humanistik dalam geografi juga masih melihat simbolisasi ruang/tempat dalam media sebagai palsu. Edward C. Relph, misalnya, geografer yang menggunakan pendekatan fenomenologis, menyatakan bahwa masyarakat tidak dapat dilihat dengan media massa. Pasalnya, identitas dalam media massa "tidaklah didasarkan pada simbol dan penandaan dan persetujuan atas nilai, tetapi pada kepalsuan dan stereotif yang dibentuk secara sewenang-wenang bahkan sintetis" (EC Relph dikutip dalam Burgess dan Gold, 1985: 17)

Ketika pendekatan behavioristik dan interpretif mengacuhkan pentingnya media dalam relasinya dengan geografi, Burges dan Gold menggunakan konsep 'budaya popular' dari perspektif Cultural Studies untuk mendorong pentingnya media dalam studi geografi. Dalam konsep budaya popular, media tidak lagi dilihat sebagai alat manipulasi, melainkan tempat ideologi sebuah kebudayaan bekerja. Media, dengan demikian, adalah praktik kultural dari keruangan. Media tidak hanya menawarkan citra/manipulasi ruang atau tempat, tetapi sebagai instrumen ideologi. Media dapat membentuk ruang. Di akhir sesi perkenalan dari buku tersebut, Burgess dan Gold (1985: 32) menulis sebagai berikut. 
Sudah menjadi niat kami dalam Pengantar ini untuk menyarankan cara-cara di mana geografer dapat mengeksplorasi beragam bentuk budaya populer dan untuk menjustifikasi keyakinan kami bahwa media harus menjadi fokus penting untuk kerja geografi. Kami berharap Geografi, Media dan Budaya Populer akan merangsang penelitian dalam disiplin ini, dan oleh karena itu kami telah menawarkan sebuah agenda penelitian awal yang mengandung banyak tantangan..."

Jika Burgess dan Gold mencoba meyakinkan disiplin geografi untuk tidak menganaktirikan media, maka Joshua Meyrowitz, yang merupakan sarjana dari Komunikasi dan terpengaruh gagasan Marshal McLuhan dan Harold Innis, membahas bagaimana media elektronik (radio dan televisi) telah mengubah ruang sosial manusia modern. Meyrowitz menulis bahwa bukunya menggambarkan bagaimana media elektronik mempengaruhi tingkah laku sosial, bukan melalui kekuatan pesan media elektronik tapi dengan bentuk mediumnya. Sebuah gagasan yang mirip dictum pendekatan teknologis Marshal McLuhan, medium is the message.

Meyrowitz menyatakan bahwa medium elektronik telah mereorganisasi ruang-ruang sosial dimana orang berinteraksi dan melemahkan relasi ketat ruang fisik dan ruang sosial. Menyandarkan diri pada gagasan Goffman, dimana identitas tergantung pada interaksi, Meyrowitz berargumen bahwa dengan adanya interaksi-interaksi mediasi elektronik, definisi manusia terhadap situasi dan perilaku tidak lagi ditentukan oleh lokasi fisik. Sebaliknya, dengan media elektronik, berpisah secara fisik dari seseorang, tidak berarti berpisah secara sosial dari seseorang tersebut. Media dengan demikian mengubah bentuk situsasi sosial dan identitas sosial.

Meyrowitz mengambil contoh penjara. Makna sosial 'penjara' sebenarnya telah diubah oleh media elektronik. Penjara tadinya adalah tempat penahanan fisik, tapi juga sekaligus tempat isolasi informasi. Seorang narapidana tidak hanya terbatas dalam gerakan, tapi juga dari komunikasi dengan masyarakat. Dengan media elektronik (radio, televisi dan telefon), banyak narapidana dapat berbagi dengan masyarakat luas (Meyrowitz, 1986: 117)

Setelah dua karya ini, riset mengenai media dan komunikasi mulai memperhatikan masalah keruangan yang dimulai pada pertengahan 1990-an. Paling tidak, studi yang berfokus pada masalah hubungan komunikasi dan ruang ini dapat dilihat dalam tiga arena. Pertama, studi sosiologi media yang mengkaji relasi interpersonal dan kelompok misalnya dalam ritual, tindak performatif, dan elemen komunal dalam komunikasi yang termediasi. Kedua, kajian yang berhubungan dengan produksi ruang baik material maupun representasional, terutama studi mengenai kota yang semakin memperluas batas studi media dan komunikasi. Ketiga, studi berperspektif makro yang mengeksplorasi peran media sebagai mesin geopolitik dan kuasa simbolik, secara khusus dalam skala global dan dalam konteks pembangunan nasionalisme (Adams \& Jansson, 2012: 300).

Pada pokoknya, pada tahapan spasial ini, ruang tidak lagi merupakan sesuatu yang begitu saja terberi, melainkan sesuatu yang dinegosiasikan oleh teknologi media dan komunikasi. Ruang adalah struktur yang dimediasi dimana dalam mediasi tersebut terdapat permainan dimensi imajiner, simbolik, dan material. Dengan demikian, posisi "konteks" yang 
biasanya didasarkan atas ruang yang tetap dan digunakan untuk memaknai teks lantas menjadi ambigu. Arti perspektif keruangan dalam Komunikasi Geografi sama sekali lain dari "asal menyadari ruang tempat fenomena komunikasi terjadi” sebagaimana dalam 'model tahapan kontekstual' (biasanya terdapat dalam studi komunikasi antarbudaya).

\section{Bidang Kajian Komunikasi Geografi Menurut Paul C. Adams}

Sebagai sebuah lapangan studi, komunikasi geografi haruslah mempunyai bidang kaji. Dalam sub-bab ini, akan dibahas bidang-bidang kaji yang mungkin muncul dalam komunikasi geografi. Pembahasan bidang kaji ini bersumber dari alternatif bidang kajian yang dikembangkan oleh Paul Adams dan Andre Jansson.

Dalam geografi, umumnya, ruang (space) dibedakan dari tempat (place). Ruang (space) adalah yang memberi posisi dan orientasi seseorang kepada sebuah tempat (place). Sementara tempat, memberi karakter atau struktur pada ruang. Ruang adalah sesuatu yang lebih abstrak sementara tempat adalah sesuatu yang lebih stabil dan lebih material. Kedua konsep tersebut dapat kita lihat, misalnya, pada pengertian 'ruang publik' (space) yang menuntun kita pada cara memperlakukan tempat-tempat (places) seperti taman kota, jalan, jembatan dan gedung sekolah.
Dengan pembedaan ruang dan tempat itu, Paul C Adams, yang bergerak dari disiplin geografi, menyatakan bahwa komunikasi geografi adalah bidang yang mempelajari relasi antara dua elemen besar dalam masing-masing bidang geografi dan komunikasi, yakni ruang (space) dan tempat (place) milik disiplin geografi dan ketegangan masalah konteks (context) dan isi (content) milik disiplin komunikasi (Adams, 2009: 2011).

Dalam pertautan dua bidang tersebut, komunikasi geografi, menurut Adams, perlu berfokus pada empat bidang kaji. Pertama, bagaimana tempat-tempat direpresentasikan dalam media (places in media). Kedua, bagaimana media dimaknai dalam tempat-tempat, dan oleh karenanya, konteks lokal tertentu (media in places). Ketiga, bagaimana media dimaknai dalam ruang-ruang tertentu (media in spaces). Keempat, bagaimana ruang-ruang direpresentasikan dalam media (spaces in media) (Adam, 2011: 39). Pada 2012, ketika Adams menulis bersama-sama dengan Andre Jansson, empat bidang ini didefinisikan dengan konsep yang lain, dan istilah media diperluas menjadi komunikasi. Keempat kutub komunikasi berubah menjadi 1) representasi, 2) tekstur, 3) struktur, dan 4) koneksi.

Bidang representasi adalah ketika komunikasi geografi membahas bagaimana tempat-tempat direpresentasikan dalam proses komunikasi (places in communication). Bidang ini terutama terkonsentrasi pada upaya verifikasi gagasan bahwa pengetahuan manusia mengenai sebuah tempat diderivasikan dari representasi tempat tersebut dalam komunikasi/media. 


\section{Bagan 2. Framework Komunikasi Geografi} (dalam Adam \& Jansson. 2012, h. 306)

\begin{tabular}{|c|c|}
\hline $\begin{array}{c}\text { REPRESENTATIONS } \\
\text { (places in communication) }\end{array}$ & $\begin{array}{c}\text { TEXTURES } \\
\text { (communication in places) }\end{array}$ \\
\hline $\begin{array}{c}\text { CONNECTIONS } \\
\text { (spaces in communication) }\end{array}$ & $\begin{array}{c}\text { STRUCTURES } \\
\text { (communication in spaces) }\end{array}$ \\
\hline
\end{tabular}

Pada peta Jawa, misalnya, yang dibuat oleh pelaut Portugis, Joao de Barros, mengenai Pulau Jawa yang didistribusikan di Eropa akhirnya mempengaruhi cara Sir Thomas Stanford Raffles mengkategorisasi Jawa menjadi dua, yakni Jawa dan Sunda (Dhona, 2016). Studi tentang bagaimana kota direpresentasikan dalam program city branding juga dapat menjadi objek studi dalam bidang kaji ini. City branding sebagai sebuah mediasi, akhirnya memproduksi sebuah kota dengan cara yang lain. Studi tentang mediasi tempat pariwisata dalam iklan atau majalah pariwisata juga dapat menjadi bagian dari bidang kaji ini. Misalnya, bagaimana Indonesia menjadi sebuah tempat dengan cita rasa global ketika ia dimediasi dalam sebuah majalah maskapai penerbangan (Dhona, 2018)

Bidang kaji tekstur adalah perihal bagaimana proses komunikasi dimaknai dalam tempat-tempat, dan, oleh karenanya, konteks lokal tertentu (communication in places). Tempat di sini tidaklah selalu berarti wilayah yang didefinisikan oleh batas-batas, tetapi dimaknai sebagai sebuah 'tekstur' yang lebih merujuk pada tindakan-tindakan komunikasi yang menyusun sebuah keruangan tertentu (Adams \& Jansson. 2012, 308). Studi ini semacam ini bisa dilihat, misalnya, istilah 'kemadjoean' di Hindia Belanda yang selalu dimaknai bersekolah, menjadi seorang yang literate. Di wilayah Sunda, hal itu dimaknai sebagai "berbeda dengan orang-orang di Jawa", tidak saja karena perbedaan wilayah antara Sunda dengan Jawa, tetapi juga, pada saat bersamaan, membentuk ruang bernama 'Sunda'. Dalam bidang ini, 'konteks' yang memberi makna pada content tidak dilihat 'sudah tersedia' sebelumnya, melainkan terbentuk pada saat proses pemberian makna itu sendiri.

Ketika orang Sunda belajar di sekolah sejak 1900, orang Sunda tak peduli lagi pada Bahasa Jawa. Kepandaian dari Jawa yang dianggap luhur oleh Orang Sunda di masa sebelumnya, pada awal abad ke-20 dinilai agak tidak berguna. Jumlah orang Sunda yang 'mesantren' di Jawa sangat langka, kalah jumlah dengan yang bersekolah. Bahkan, seorang Kiai Sunda enggan memaknai ayat Quran dengan Bahasa Jawa sebagaimana biasanya (Dhona, 2015: 179). Pemaknaan orang Sunda tersebut pada 'kemajuan' (bahwa kemajuan adalah upaya pembedaan dengan 'Jawa) tidak lahir karena sebelumnya sudah ada pengertian 'Sunda' yang definitif, melainkan pemaknaan kemajuan tersebut memerikan batas apa Sunda itu.

Berikutnya adalah struktur. Ini adalah bidang kaji dimana ia mempelajari bagaimana jalannya proses komunikasi antara ruang-ruang tertentu pada akhirnya membentuk hierarki atau menstrukturkan 
ruang-ruang tersebut (communication in spaces). Komunikasi disini dimengerti sebagai jalur atau saluran atau pola gerak yang semi-tetap. Misalnya, bagaimana infrastruktur dan teknologi komunikasi pada akhirnya melahirkan jenis keruangan tertentu seperti 'negara maju' dan 'negara dunia ketiga', atau 'kawasan urban', 'kawasan perdesaan', dan sebagainya. Komunikasi yang dijalin oleh Direktorat Jendral Pendidikan Tinggi kepada perguruan-perguruan tinggi pada akhirnya memunculkan kategori atau status Perguruan Tinggi; 'BHP', 'BLU' atau 'Satuan Kerja'.

Model penelitian bidang kaji ini adalah gagasan 'geometri kuasa' (power geometries) dari Doreen Massey (1991: 290). Ia mengemukakan bahwa konvergensi ruang-waktu pada akhirnya hanya melahirkan ketidaksamaan. Massey memberikan contoh perbandingan kecepatan perusahaan multinasional dan pekerja migran. Kondisi dan situasi keruangan 'perusahaan multinasional' memungkinkan mereka lebih cepat bergerak mengelilingi dunia ketimbang 'pekerja migran' atau 'pengungsi politik'.

Terakhir adalah koneksi. Ia adalah perihal bagaimana ruang-ruang dibentuk dalam sebuah proses komunikasi (spaces in communication). Dimensi ini mengandaikan bahwa ruang selalu dihasilkan oleh, untuk, dan dalam sebuah hubungan/koneksi dari komunikasi yang termediasi. Dalam hal ini, Adams memberikan contoh yang menarik mengenai bagaimana hubungan orang non-tuli dan orang tuli pada akhirnya membentuk sebuah ruang inklusi dan ekslusi orang tuli melalui bahasa, institusi, dan teknologi. Dalam bahasa, formalisasi dan pengajaran bahasa melalui mata ketimbang telinga adalah pembentukan ruang dalam bahasa bagi orang tuli. Usaha untuk memperlakukan si tuli sebagai orang yang kompeten dalam berbahasa ketimbang memarjinalisasi mereka, pada saat yang sama mengantarkan si tuli pada ruang sosial yang, pada faktanya, tidak bisa diakses oleh orang banyak (Adams, 2009: 47).

\section{Bidang Kaji Komunikasi Geografi Menurut Andre Jansson}

Paul C. Adams melihat komunikasi geografi sebagai hubungan diadik antara disiplin komunikasi dan disiplin geografi yang menimbulkan adanya empat bidang kajian. Sementara itu, Jansson menawarkan tiga bidang kaji utama. Andre Jansson berangkat dari konsep 'tekstur', konsep yang dipopulerkan oleh Henri Lefebvre. Secara sederhana, tekstur adalah apa saja yang membuat kita berkeyakinan bahwa sebuah ruang/tempat tertentu sebagai tetap/konstan dan sebaliknya berubah. Tektur adalah 'struktur' yang membuat kita meyakini bahwa ruang adalah 'sebuah ruang' tertentu dengan batasan dan property tertentu. Fokus Jansson, dalam hal ini, adalah bagaimana hubungan hal-hal yang simbolik (media, komunikasi dan pengetahuan keruangan) dengan hal-hal yang material (tempat, rumah, ruang kantor, batas kota dll).

Jansson mengajukan tiga bidang komunikasi geografi. Pertama bidang kaji mengenai representasi-representasi ruang atau proses mediasi ruang (mediation of space). Kedua adalah bidang kaji untuk masalah bagaimana ruang termediatisasi (mediatisation of space). Ketiga adalah kajian mengenai pengalaman keruangan individu yang termediatisasi (a mediatised sense of space). (Jansson, 2017: 99).

Dalam kasus perubahan ruang atau perubahan skala ruang, ketiganyalah dimensi yang membentuk skala-skala ruang, lokal-regional atau global. 
Ketiga bidang ini sebenarnya mengikuti tiga dimensi ruang sebagai produk sosial milik Henri Lefebvre (1991), yakni spatial practices, representations of space; spaces of representation/ representational space. Jansson mengingatkan bahwa ketiga bidang tersebut selalu berada dalam hubungan dan harus dipahami sebagai 'variasi perspektif' (Jansson, 2017: 97), meski demikian ia setuju jika ketiganya dapat dijadikan sebagai alternatif bidang kaji guna merespon perkembangan studi komunikasi geografi (Korespondensi pribadi, 23 Oktober 2017).

Bidang kaji pertama yang digagas Jansson adalah mediasi ruang (mediation of space). Bidang kaji mengenai mediasi simbolik dari ruang seperti peta, gambar atau apapun bentuk representasi yang menunjukkan ruang sebagaimana dia dulunya, sekarang atau bahkan di masa datang. Jadi, bidang kaji ini terkait dengan konstruksi dan sirkulasi representasi ruang via media atau tindakan komunikasi (misalnya pemberitaan internasional, branding kota/tempat wisata). Objek yang dapat diteliti adalah content mediasi (pesan mediasi), aktor dan atau institusi yang terlibat dalam produksi mediasi dan juga penerimaan khalayak pada sebuah mediasi (persepsi, resepsi, reading/decoding). Termasuk dalam kajian adalah analisis iklan Meikarta, sebuah kota yang merupakan proyek Lippo Group (Remotivi, 2017). Kajian ini tidak hanya menganalisis bagaimana Meikarta digambarkan, tapi juga menyimpulkan bahwa mediasi Meikarta dalam iklan ini adalah perwujudan dari bagaimana jauhnya kota dari jangkauan warga Jakarta. Warga Jakarta tidak dilibatkan dalam membenahi atau mendefinisikan Jakarta.

$$
\text { Bidang kaji kedua adalah }
$$
mediatisasi ruang (mediatisation of space). Ini adalah kajian terhadap aktivitas dan kondisi material yang terjadi dalam ruang yang dengan tindakan tersebut ruang menjadi terdefinisikan. Selain itu, bidang kaji ini juga mencakup bagaimana penyerapan dan ketergantungan pada media berdampak pada pembentukan ruang. Praktik visualisasi perempuan dengan bikini pada majalah pria dewasa, misalnya, menjadikan majalah pria dewasa dapat dikatakan sebagai "ruang bagi pria yang telah dewasa”. Kajian lain juga bisa dilihat dari perubahan perilaku manusia atas ruang restoran karena media. Jika awalnya manusia pergi ke restoran untuk melakukan aktivitas makan, maka di zaman sosial media makan bukan menjadi aktivitas satu-satnya. Sebaliknya, berfoto bersama, mengambil gambar makanan atau papan nama restoran dan lalu mengunggahnya ke media sosial.

Bidang kaji ketiga adalah pengalaman keruangan individu yang termediatisasi. Bidang ini sebenarnya menggantikan dimesi ruang-ruang representasi (spaces of representation/ representational space) pada teori ruang Lefebvre. Kajian ini fokus pada fakta imajinasi dan pengalaman individu atas ruang yang tidak hanya terdiri dari mitosmitos dan ideologi, tapi juga harapan atas ruang. Kajian ini bisa dilihat dari, misalnya, kunjungan kita ke Kotagede, Yogyakarta, yang sekadar untuk mengambil foto pintu dan jendela lawas dari rumah-rumah kuno yang ada di sana karena foto-foto itu populer di Instagram. Harapan kita atas ruang Kotagede terbentuk melalui media sosial Instagram (Dhona, 2018). Media sosial Instagram tidak hanya mengajari tentang sudut-sudut yang cocok untuk difoto, tetapi juga sampai pada cara mengambil foto apakah dengan meloncat, duduk atau posisi yang lain. Cara mengambil foto adalah 'cara mengalami sebuah ruang', dan hal tersebut ditata oleh media. 
Penting dicatat bahwa dalam
gagasan Jansson terdapat konsep
mediatisasi yang 'dianggap' sudah jadi. Mediatisasi adalah bagaimana logika media terserap dalam institusi lain, lapangan dan sistem kehidupan sosial lainnya (Hepp,. 2013: 40). Alhasil, dalam gagasan Jansson, konsep mediatisasi seolah-olah mengandaikan determinasi media dalam kehidupan sosial. Konsep mediatisasi, singkatnya, adalah perwujudan gagasan determinisme teknologi. Menurut Jansson, mediatisasi yang ia gunakan lebih bersifat dialektis dimana ia bermakna "perubahan kualitatif dalam hubungan sosio-material dimana terdapat peningkatan tertentu kapasitas manusia untuk aktivitas material, sosial atau budaya yang dimungkinkan oleh media. Ini sekaligus merupakan penurunan otonomi individu atau institusi” (Jansson, 2017: 101). Dengan demikian, konsep mediatisasi tidaklah berarti mengakui determinasi media/teknologi media pada subjek (baik individu maupun kolektif), tetapi disediakan untuk melihat bagaimana tarik ulur keterpengaruhan antara subjek dan teknologi media/struktur dalam membuat ruang. Penerimaan teknologi sebagai sebab dalam relasi sosial dan proses komunikasi, bukan berarti menerima kemutlakan teknologi (determinisme teknologi) atas realitas sosial (Falkheimer \& Jansson, 2006: 16)

\section{Kesimpulan}

Komunikasi adalah sebuah proses, tapi bukan hanya 'proses transmisi pesan', melainkan proses yang tidak pernah tetap karena ia adalah produk dari keruangan dan kekhasannya. Sebaliknya, sebuah ruang atau keruangan juga tidak pernah statis, melainkan dinamis dan merupakan produk proses komunikasi. Komunikasi geografi adalah sub disiplin dari komunikasi yang dilahirkan untuk menjawab masalah ambiguitas relasi hubungan ruang dan komunikasi.

Dengan kelahiran sub-disiplin komunikasi geografi, disiplin komunikasi tidak hanya mendapatkan cabang baru, tetapi juga patut menimbang definisi komunikasi lain, yakni komunikasi sebagai "proses produksi ruang" (communication as spatial production) dengan ruang yang selalu situasional dan dinamis.

Artikel ini barangkali hanya mengulang apa yang telah disajikan para sarjana komunikasi yang menjadikan ruang dan media/komunikasi sebagai fokus area riset seperti gagasan Harold Innis, Joshua Meyrowitz, dan sarjana lainnya. Namun, dengan minimnya penggunaan kata kunci 'komunikasi geografi' atau 'media geografi' atau 'geografi komunikasi' di pustaka kajian komunikasi di Indonesia, seruan untuk menekuni area riset ini, dan deklarasinya sebagai area riset tersendiri adalah satu kemungkinan bagi pengembangan wilayah baru studi-studi akademik komunikasi di Indonesia. [] 


\section{DAFTAR PUSTAKA}

Adams, P. C. (2009). Geographies of media and communication: A critical introduction. Chichester, U.K: WileyBlackwell.

(2011). A Taxonomy of Communication Geographies in Progress in Human Geography 35(1), h 37-57.

Adams, PC., \& Jansson, A. (2012). Communication geography: A bridge between disciplines. Communication Theory, 22(3), 299-318. https://doi.org/10.1111/j.14682885.2012.01406.x

Adams, PC., Craine, J., \& Dittmer, J. (2016). The Ashgate research companion to media geography. London: Routledge.

Adams, PC., Cupples, J., Glynn, K., Jansson, A., \& Moores, S. (n.d.). 2017. Communications / Media / Geographies. New York, Routledge

Anderson, B.R.O. G (2002). Imagined Communities, KomunitasKomunitas Terbayang. Yogyakarta : Insist Press \& Pustaka Pelajar

Burgess, J., \& Gold, J. R. (1985). Geography, the media \& popular culture. London: Croom Helm.

Carey, James W. 2009. Communication as Culture, Essay on Media and Society Revised Edition. New York \&London; Routledge
Dhona, HR. (2018) Tidak perlu yang asli, yang penting selfie: fenomena di balik Rabbit Town. The Conversation.com, 16 April dapat diakses di https://theconversation.com/tidakperlu-yang-asli-yang-penting-selfiefenomena-di-balik-rabbit-town94857

(2017). Memikirkan Ulang Media Dalam Komunikasi Geografi. Remotivi, o7 April dapat diakses di http://www.remotivi.or.id/kupas/37 4/Memikirkan-Ulang-Media-dalamKomunikasi-Geografi

(2016). The Role Of Modern Communication Technology In The Invention of The Geobody Of Sundanese, Proceeding in the 2 nd World Conference on Media and Mass Communication Vol. 1 h, 27-33 . (2015). Wacana Kemadjoean Di Kelompok Etnis Sunda Awal Abad 20. Jurnal Informasi UNY. Vol. 45 (2). 171-182

Falkheimer, J., \& Jansson, A. (2006). Geographies of communication: The spatial turn in media studies. Göteborg: Nordicom.

Hadi, BS. (2006). Diktat Kuliah Geografi Komunikasi. Jurusan Pendidikan Geografi Fakultas Ilmu Sosial Dan Ekonomi Universitas Negeri Yogyakarta 
Hall, Stuart (2015). Encoding/Decoding dalam Hall, S., Hobson, D., Lowe, A., Willis, P. E., Routledge., \& University of Birmingham. Culture, media, language: Working papers in cultural studies, 1972-79. Abingdon, Oxon: Routledge. Hal; $117-127$

Hepp, A. (2013). Cultures of mediatization. Cambridge: Ma.

Jansson, A. (2005). For a Geography of Communication. Axelsoon \& Fornas (ed) Paper från ACSIS nationella forskarkonferens för kulturstudier, Norrköping 13-15 juni, h. 1-16 (www.ep.liu.se/ecp/o15/)

Jansson. A. (2017). Critical Communication Geography, Space, recognition, and the dialectic of mediatization dalam Adams, P. C., Cupples, J., Glynn, K., Jansson, A., \& Moores, S. (n.d.). Communications / Media / Geographies, h; 95-131

Kriyantono, R \& McKenna, B. (2017). Developing a Culturally-Relevant Public Relations Theory for Indonesia. Jurnal Komunikasi, Malaysian Journal of Communication, Jilid 33 (1), h. 1-16
Kusuma, RS \& Vitasari, Y (2017). Gendering the Internet: Perempuan pada Ruang Gender yang Berbeda. Jurnal Ilmu Komunikasi Volume 14 (1) Juni 2017. h. 125-142

Massey, DB. (2007). Spaces of Politic dalam Massey, D. B., In Allen, J., \& Sarre, P. Human geography today.h. 279-294

Meyrowitz, J. (1986). No sense of place: The impact of electronic media on social behavior. New York: Oxford University Press.

Mulyana, Deddy. 2009. Ilmu komunikasi; suatu pengantar. Bandung : Remaja Rosdakaraya

Remotivi. (2017) Wajah Kota dalam Meikarta.

(https://www.youtube.com/watch?v $=$ wzj3jKG91No)

Simonson, P. (2013). Handbook of communication history. New York: Routledge. 